\title{
Chairpersons' Summary
}

\section{The Fifth Asian Conference on Scientific} Cooperation

\section{-Forum of Scientists -}

\author{
March 11-13, 1998 Tokyo, Japan
}

1. The Science Council of Japan (JSC) has been hosting the Asian Conference on Scientific Cooperation(ACSC) since 1993 and the Fifth Conference was held with prominent scientists from China, India, Indonesia, Republic of Korea, Malaysia, the Philippines, Singapore, Thailand, Viet Nam and the host country, Japan, at JSC in Tokyo from March 11 to 13, 1998. The main theme of the Fifth Conference was "Urgent Tasks Facing Science in Asia: Towards Sustainable Development."

2. The participants were privileged to meet with H. E. the Prime Minister R. Hashimoto at his residence. The Prime Minister expressed his pleasure that JSC was hosting the 5th Asian Conference on Scientific Cooperation and encouraged Asian scientists to make greater contributions for sustainable development in the region.

3. In the opening of the Conference, Dr. Hiroyuki Yoshikawa, President of JSC, gave a keynote lecture under the theme "The Role of Sciences in Sustainable Development". He emphasized that the reformation of the discipline system is necessary for sustainable development, which undoubtedly requires integrated collaboration of researchers from various fields, not only of the sciences, but also the humanities. Collaboration among researchers in different domains; between the government, corporations and academia, and between different countries which have different cultures, will be crucial for the success of the actions to save the environment. Tan Sri Datuk Dr. Omar Abdul Rahman, President of the Academy of Sciences Malaysia, delivered also the other keynote lecture under the theme "Urgent Task in Asia: Ensuring Sustainability of National S\&T System to Ensure Sustainable Development”. He pointed out that the urgent task is twofold: (1) Improve the S\&T Advisory System (including the environment) to ensure policy integration; (2) Adopt the Technology Management approach to ensure sustainable S\&T development and delivery system. These actions can be enhanced through public-private 
sector cooperation at national and international levels using the Smart Partnership approach and framework.

4. On the second day, the Academic Symposium was held. In the morning, three delegates gave special lectures. Dr. Srinivasan Varadarajan, President of the Indian National Science Academy, gave a lecture entitled "Shared Asian Vision and Strategies". Dr. Toshinosuke Kashiwazaki, Vice-President of JSC, spoke on "The Role of the Science toward Social Betterment, with Special Reference to Asia”. Prof. Dr. Montri Chulavatnatol, President of the Science Society of Thailand delivered the lecture, "Science in Asia: the Name of the Game is to Win". In the afternoon, two panel discussions were held under the themes "What the Research Environment in Science should be" and "How Science should Cope with Global Scale Problems". Through discussion on global and environmental problems for which the entire world must cooperate, the participants recognized the importance of scientific cooperation in Asia in the future. Especially in Asia, population, food, energy and environment are vital issues for sustainable development. Science and Technology plays a key role in dealing with these issues. The need for integration of social and natural sciences was stressed in the symposium.

5. In the second and third days' sessions, discussions were held regarding the future activities of ACSC. The conference emphasized the importance of mutual understandings for scientific cooperation in Asia in the future and confirmed the usefulness of discussion in academic symposia and scientific conferences. In recognition of the need to make every effort to achieve its common scope and goal, ACSC will be developed to a more suitable structure namely, the Science Council of Asia (SCA), as proposed by the Task Force established by ACSC in 1997. A delegation from JSC will be visiting ACSC countries for further consultation on the formation and organization of SCA before finalizing the proposal.

6. As the first step for the realization of its objectives, ACSC concurred with the proposal to establish the Organization for the Development of Chemistry and Chemical Technology in Asia (ODCA), which was proposed in the 2nd ACSC in 1995, and has been discussed since then.

7. The participants welcomed the proposal that ACSC should be held by JSC at least until 2000. The next (6th) ACSC will be held in 1999, which will mark the 50th anniversary of JSC. The participants agreed that it should be held in Tokyo by JSC under the theme "Population and Environment - Asia's Critical Role in Sustainable Development".

8. The participants expressed their very sincere appreciation to JSC for organizing the 5th ACSC and for their excellent support and hospitality. 